\title{
Characteristic of a Suspended Media Bed to Reduce or Eliminate Clogging in Subsurface Constructed Wetland
}

\author{
Meng Cai ${ }^{1}$, Yongxiang Ren ${ }^{2 *}$, Ge Bai ${ }^{2}$, Qiuhui Yan $^{2}$ \\ ${ }^{1}$ XAUAT UniSA An De College, Xi' an University of Architecture and Technology, 710311 Xi'an, Shaanxi, China \\ ${ }^{2}$ Key Laboratory of Environmental Engineering of Shaanxi Province, 710055 Xi'an, Shaanxi, China
}

\begin{abstract}
Clogging is a common and difficult problem in subsurface flow wetlands. In this study, 2-4mm, $4-8 \mathrm{~mm}, 8-10 \mathrm{~mm}$ lightweight ceramsite were used as suspended media beds and $5-10 \mathrm{~mm}$ gravel was used as traditional substrate bed as control. The effects of these four substrate beds on the purification of water quality and the change of flow capacity in the clogging process in the non-deformable inorganic particle wastewater, deformable inorganic particle wastewater and organic particle wastewater were studied. After the beds were clogged, using the characteristics of lightweight ceramsite floating up and down with water level, the mitigation effect of clogging with water level fluctuation at different heights $(10 \mathrm{~cm}, 20 \mathrm{~cm}, 30 \mathrm{~cm}, 40 \mathrm{~cm})$ was explored. The results showed that four kinds of beds had effect on the removal of turbidity and suspended particles. The beds in the treatment of non-deformable inorganic particle wastewater were more likely to cause wetland gap clogging; In the absence of plants, compared with inorganic particles, the clogging degree of substrate in the treatment of organic suspended particulate wastewater was not obvious. After clogging, lightweight ceramsite floats up and down with the water level, three kinds of wetland clogging have been alleviated to some extent.
\end{abstract}

\section{Introduction}

As a new type of water treatment technology to improve the ecology, constructed wetland has been widely recognized and applied in the world because of its low construction cost, simple operation and maintenance, and good treatment effect. However, after a period of actual operation, the subsurface flow constructed wetland will have clogging problems. According to the USEPA (U.S. Environmental Protection Agency) survey, it is found that about $50 \%$ of the more than 100 constructed wetlands that have been put into use will show varying degrees of clogging within 5 years of operation. The constructed wetlands established in the early days of China also experienced blockages to varying degrees [1]. Wetland clogging not only reduces the effect of sewage purification treatment, but also shortens the service life of constructed wetlands, increases maintenance costs, and greatly limits the promotion and application of constructed wetlands.

In order to solve the clogging problem of constructed wetlands, the existing solutions are mainly divided into two aspects, one is preventive treatment [2], and the other is to take restorative measures [3]. Specific measures for preventive treatment include setting up pre-treatment facilities such as sedimentation tanks; improving wetland substrate; controlling hydraulic loads; and changing wetland operating conditions. Huang et al. [4] increased the service life of the wetland to 2.77 times of the original system by optimizing the structure and technology of the composite vertical flow wetland. The restorative measures include the replacement of refurbished fillers; the addition of chemicals; and the addition of small organisms such as earthworms. However, these measures require relatively high costs, are difficult to control, and are likely to have a certain impact on the growth environment of plants and microorganisms. Therefore, it is essential to take new measures to solve wetland clogging. Lightweight ceramsite is commonly used for planting, and its lightness is the most important property. The lightweight ceramsite can float up and down with the changes of water level. Based on this characteristic, this study intends to use lightweight ceramsites as wetland substrate. When the lightweight ceramsites float up and down, the substrate gaps can be recombined from time to time, and then the clogging pollutants can fall off. And the problem of easy clogging of subsurface wetlands can be reduced or even eliminate.

\section{Materials and Methods}

\subsection{Experimental set-up}

This experiment uses an upward subsurface flow constructed wetland, and the devices are placed in the laboratory. The devices are made of acrylic tube, with a height of $100 \mathrm{~cm}$ and a diameter of $5 \mathrm{~cm}$, which are respectively filled with $5-10 \mathrm{~mm}$ gravel and $2-4 \mathrm{~mm}$, 4$8 \mathrm{~mm}$, and $8-10 \mathrm{~mm}$ light ceramsites after sieving and

*Corresponding author: ryx@xauat.edu.cn 
cleaning. The filling height is $60 \mathrm{~cm}$. The test device is shown in Figure 1. The artificial water distribution is evenly stirred by a magnetic stirrer and then flows into the four groups of submerged wetlands. The bottom of the container is equipped with a drainage port, and asampling port is set at a height of $60 \mathrm{~cm}$ from the bottom. The sewage enters from the bottom through the water inlet pipe and flows upward through the substrate and then flows out from the sampling port. The devices use intermittent inflow water, the hydraulic retention time is 2 days, and the test lasts for a total of 40 days.

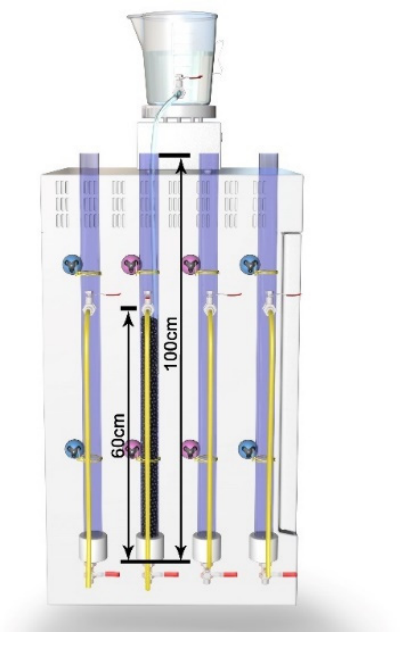

Fig. 1. Suspended Media Bed Schematic

\subsection{Method of wetland clogging}

Four groups of test devices have the same state before operation, and no plants are planted. 1500 mesh bentonite and 2000 mesh zeolite powder are used to simulate the clogging of inorganic particles, and corn starch is used to simulate the clogging of organic particles. Bentonite has the characteristics of swelling when exposed to water and deformable. The surface of zeolite powder is smooth and non-deformable, and it has non-Newtonian fluid characteristics same as corn starch. The influent suspended particulate matter (SS) concentration is $45.63 \mathrm{~g} / \mathrm{L}$. The water purification ability of wetland substrate bed is characterized by measuring the removal rates of SS and turbidity. The flow capacity of wetland filler bed is characterized by measuring the permeability coefficient. According to Tong et al. [5], when the flow permeability coefficient reaches $1.61 \times 10^{-3} \mathrm{~cm} / \mathrm{s}$, the wetland can be defined as clogging. On this basis, the devices run for 40 days.

\subsection{Method of clogging mitigation}

After the suspended media beds are clogged, the substrate particles are rearranged by adjusting the bed to rise $10 \mathrm{~cm}$, $20 \mathrm{~cm}, 30 \mathrm{~cm}$, and $40 \mathrm{~cm}$ with the water level respectively, and the permeability coefficient is measured to characterize the flow capacity of the wetland substrate bed after dredging.

\subsection{Measurement of permeability coefficient}

Darcy's formula is used to determine the permeability coefficient. The measurement method is to measure the liquid level difference of the two pressure measuring tubes of the device, and then use the Darcy's formula to obtain the permeability coefficient, as shown in equation (1).

$$
k_{\mathrm{T}}=Q L / A H t
$$

where: $\mathrm{k}_{\mathrm{T}}$ is the permeability coefficient of the sample when the water temperature is $\mathrm{T}^{\circ} \mathrm{C}, \mathrm{cm} / \mathrm{s}$; $\mathrm{Q}$ is the amount of water permeated within seconds of time $\mathrm{t}, \mathrm{cm}^{3}$; $\mathrm{L}$ is the length of subtrate, $\mathrm{cm}$; $\mathrm{A}$ is the sample sectional area, $\mathrm{cm}^{2}$; $\mathrm{H}$ is average head difference, $\mathrm{cm}$; $\mathrm{t}$ is time, $\mathrm{s}$.

Because temperature affects the permeability coefficient, it is converted into the permeability coefficient when the water temperature is $20^{\circ} \mathrm{C}$ according to formula (2):

$$
k_{\mathrm{T}}=k_{20} * \eta_{T} / \eta_{20}
$$

where: $\mathrm{k}_{20}$ is the permeability coefficient of the sample when the water temperature is $20^{\circ} \mathrm{C}, \mathrm{cm} / \mathrm{s} ; \mathrm{k}_{\mathrm{T}}$ is the permeability coefficient of the sample at water temperature $\mathrm{T}^{\circ} \mathrm{C}, \mathrm{cm} / \mathrm{s} ; \eta_{\mathrm{T}}$ is the dynamic viscosity coefficient of water at $\mathrm{T}^{\circ} \mathrm{C}, \mathrm{kPa} \cdot \mathrm{s} ; \eta_{20}$ is the dynamic viscosity coefficient of water at $20^{\circ} \mathrm{C}, \mathrm{kPa} \cdot \mathrm{s}$.

In order to compare and analyze the difference of the permeability coefficient changes of the four substrate, the measured permeability coefficients are normalized, that is, they are divided by the corresponding initial permeability coefficients respectively, so as to obtain the proportion of each value to the initial value to characterize the wetland substrate bed degree of clogging or recovery.

\section{Results \& Discussion}

\subsection{Removal characteristics of SS and turbidity by suspended media bed}

The removal rate of SS and turbidity by the four kinds of substrate for the simulated wastewater containing three different suspended matter, shows a trend of first rising and then falling, as shown in Figure 2 (take zeolite powder as an example). This may be because as the degree of clogging increases, the ability of substrate to absorb and trap pollutants decreases, resulting in poor effluent water quality. The average removal rate of SS and turbidity in the three kinds of wastewater by the four substrate is shown in Table 1-2. It can be seen that for zeolite powder wastewater, the order of the removal rate of SS and turbidity in the water is $5-10 \mathrm{~mm}$ gravel $>4-8 \mathrm{~mm}$ ceramsite $>8-10 \mathrm{~mm}$ ceramsite $>2-4 \mathrm{~mm}$ ceramsite; for bentonite wastewater, the order is $2-4 \mathrm{~mm}$ ceramsite $>4$ $8 \mathrm{~mm}$ ceramsite $>5-10 \mathrm{~mm}$ gravel $>8-10 \mathrm{~mm}$ ceramsite; for starch wastewater, the order is $4-8 \mathrm{~mm}$ ceramsite $>2-4 \mathrm{~mm}$ ceramsite $>5-10 \mathrm{~mm}$ gravel $>8-10 \mathrm{~mm}$ ceramsite. For the same substrate, the order of SS and turbidity removal rate is zeolite powder $>$ starch $>$ bentonite. This is because bentonite takes a certain time to expand after encountering water. It may be that the hydraulic retention time of the test is too short to be deformed, and the bentonite particles have been taken away by the water flow before they are completely deformed. Therefore, the removal rate of SS in 
the incoming and outgoing water is low, and the SS removal effect is poor. It can be seen that the four kinds of substrate have poor water purification capabilities for bentonite wastewater, and have a better removal rate for zeolite powder and starch.

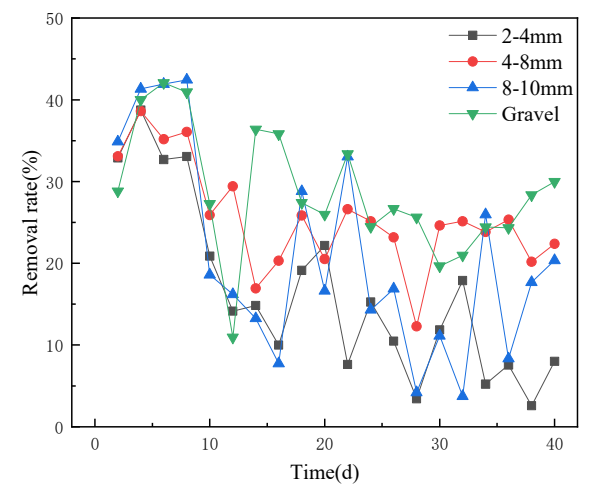

(a) SS

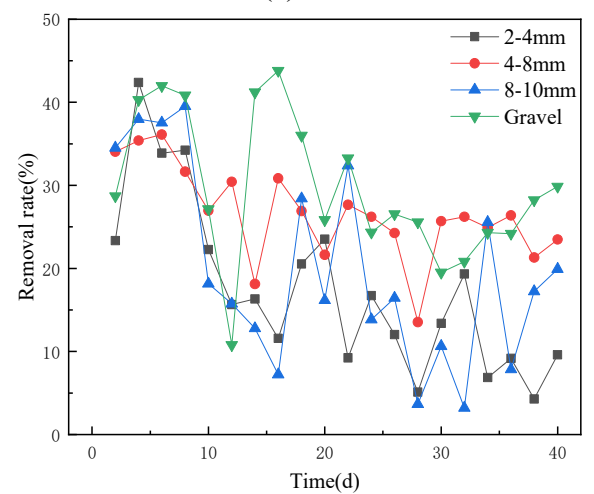

(b) Turbidity

Fig. 2. Removing rate of SS and turbidity by four fillers in zeolite powder wastewater

Table 1. The average removal rate of SS from different sources by different packed beds.

\begin{tabular}{|c|c|c|c|}
\hline $\begin{array}{c}\text { Type of } \\
\text { substrate }\end{array}$ & Zeolite & Bentonite & Starch \\
\hline $\begin{array}{c}2-4 \mathrm{~mm} \\
\text { ceramsite }\end{array}$ & $16.42 \%$ & $17.08 \%$ & $16.60 \%$ \\
\hline $\begin{array}{c}4-8 \mathrm{~mm} \\
\text { ceramsite }\end{array}$ & $25.53 \%$ & $10.32 \%$ & $21.15 \%$ \\
\hline $\begin{array}{c}8-10 \mathrm{~mm} \\
\text { ceramsite }\end{array}$ & $20.87 \%$ & $4.43 \%$ & $11.88 \%$ \\
\hline $\begin{array}{c}5-10 \mathrm{~mm} \\
\text { gravel }\end{array}$ & $28.68 \%$ & $4.71 \%$ & $17.85 \%$ \\
\hline
\end{tabular}

Table 2. The average removal rate of turbidity from different sources by different packed beds.

\begin{tabular}{|c|c|c|c|}
\hline $\begin{array}{c}\text { Type of } \\
\text { substrate }\end{array}$ & Zeolite & Bentonite & Starch \\
\hline $\begin{array}{c}2-4 \mathrm{~mm} \\
\text { ceramsite }\end{array}$ & $17.47 \%$ & $6.96 \%$ & $15.44 \%$ \\
\hline $\begin{array}{c}4-8 \mathrm{~mm} \\
\text { ceramsite }\end{array}$ & $26.59 \%$ & $5.05 \%$ & $15.77 \%$ \\
\hline $\begin{array}{c}8-10 \mathrm{~mm} \\
\text { ceramsite }\end{array}$ & $20.94 \%$ & $4.00 \%$ & $8.97 \%$ \\
\hline $\begin{array}{c}5-10 \mathrm{~mm} \\
\text { gravel }\end{array}$ & $34.06 \%$ & $4.55 \%$ & $13.79 \%$ \\
\hline
\end{tabular}

\subsection{Characteristics of clogging process of substrate beds}

The initial permeability coefficients of $2-4 \mathrm{~mm}, 4-8 \mathrm{~mm}, 8-$ $10 \mathrm{~mm}$ ceramsite and $5-10 \mathrm{~mm}$ gravel are $0.6964 \mathrm{~cm} / \mathrm{s}$, $0.7267 \mathrm{~cm} / \mathrm{s}, 0.8143 \mathrm{~cm} / \mathrm{s}$ and $0.7912 \mathrm{~cm} / \mathrm{s}$, respectively. It can be seen from Figure 3 that in the clogging process formed by three different kinds of SS, the permeability coefficients changes of the four substrate all show a decreasing trend with time. The smaller the particle size of the substrate, the smaller the initial permeability coefficient. As time increases, the cumulative amount of SS gradually increases. The faster the permeability coefficient decreases, the faster the substrate is clogged. Table 3 shows the permeability coefficients of the four substrate beds at the end of clogging. At the end of the clogging, the permeability coefficient of the same substrate in the clogging formed by bentonite is greater than the other two; the permeability coefficient of $2-4 \mathrm{~mm}$ and $4-8 \mathrm{~mm}$ ceramsite in starch is higher than that in zeolite powder; the permeability coefficient of $8-10 \mathrm{~mm}$ ceramsite and $5-10 \mathrm{~mm}$ gravel in zeolite powder is higher than that in starch. This indicates that the four substrate beds are more prone to clogging when treating non-deformable inorganic particulate wastewater; in the absence of plants, compared to inorganic particulate clogging, the degree of clogging of the substrate is not obvious when treating wastewater containing organic suspended particulates.

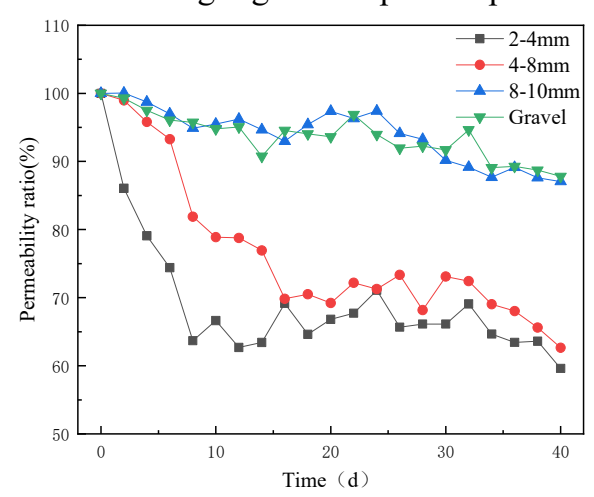

(a) Zeolite

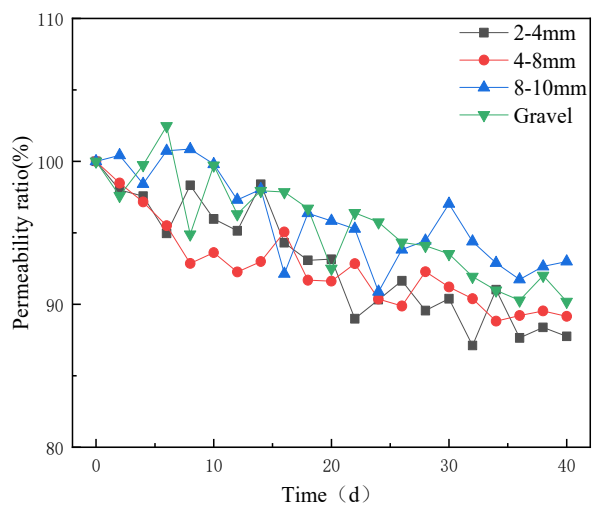

(b) Bentonite 


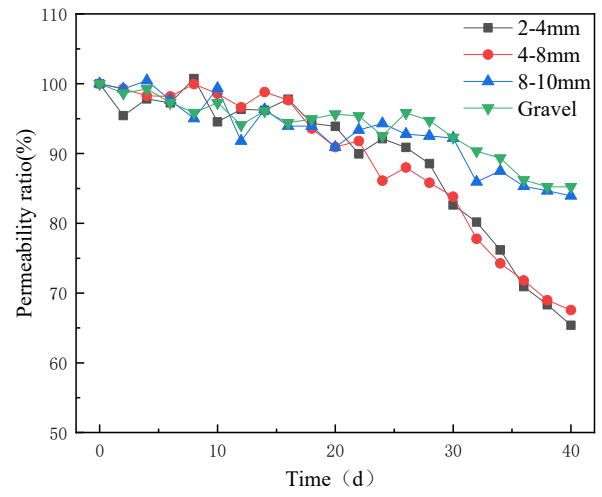

(c) Starch

Fig. 3. The permeability coefficient of different fillers in different wastewater varies with time

Table 3. Permeability coefficient of different packed beds at the end of plugging in wastewater from different sources.

\begin{tabular}{|c|c|c|c|}
\hline $\begin{array}{c}\text { Type of } \\
\text { substrate }\end{array}$ & Zeolite & Bentonite & Starch \\
\hline $\begin{array}{c}2-4 \mathrm{~mm} \\
\text { ceramsite }\end{array}$ & $0.4152 \mathrm{~cm} / \mathrm{s}$ & $0.6111 \mathrm{~cm} / \mathrm{s}$ & $0.4553 \mathrm{~cm} / \mathrm{s}$ \\
\hline $\begin{array}{c}4-8 \mathrm{~mm} \\
\text { ceramsite }\end{array}$ & $0.4554 \mathrm{~cm} / \mathrm{s}$ & $0.6479 \mathrm{~cm} / \mathrm{s}$ & $0.4909 \mathrm{~cm} / \mathrm{s}$ \\
\hline $\begin{array}{c}8-10 \mathrm{~mm} \\
\text { ceramsite }\end{array}$ & $0.7090 \mathrm{~cm} / \mathrm{s}$ & $0.7573 \mathrm{~cm} / \mathrm{s}$ & $0.6835 \mathrm{~cm} / \mathrm{s}$ \\
\hline $\begin{array}{c}5-10 \mathrm{~mm} \\
\text { gravel }\end{array}$ & $0.6948 \mathrm{~cm} / \mathrm{s}$ & $0.7136 \mathrm{~cm} / \mathrm{s}$ & $0.6744 \mathrm{~cm} / \mathrm{s}$ \\
\hline
\end{tabular}

\subsection{Effect of floating on clogging of suspended media bed}

For clogging formed by three kinds of SS, when the lightweight ceramsite rises with the water level, the permeability coefficient of three particle sizes of bed gradually increases and becomes stable with the increase of dredging times, and the higher the substrate rises, the less dredging times are required to restore the permeability coefficient to the maximum, which is shown in Figure 4 (take the most clogged zeolite powder as an example). The substrate fluctuates up and down with the water level by $10 \mathrm{~cm}$ only once, and the permeability coefficient of the clogging bed due to different SS sources recover at least $39 \%$. At different levels of fluctuation, the permeability coefficient can be restored to $92 \%$ of the initial value.

Table 4 shows the maximum value of the permeability coefficient of ceramsites with three particle sizes after being dredged under the clogging caused by different SS sources. It can be seen that this dredging method has the best recovery effect on the clogging of organic particles formed by starch, followed by zeolite powder, and bentonite has the worst recovery effect. This is because bentonite swells in water and deforms, reducing the gaps between substrate, making the degree of clogging between substrate higher than that of zeolite powder and starch. Correspondingly, when the same degree of dredging is performed, the recovery effect of clogging formed by bentonite is weaker than that of zeolite powder and starch. The dredging effect of starch is higher than the other two. This is because the wetland systems are only physically clogged. Without plants, starch cannot be degraded by plants and microorganisms to form biological blockages. Therefore, this dredging method alleviates the impact of the blockage formed by the suspended matter intercepted by the filler in the gap on the wetland. It can also be seen that there are certain differences in the recovery of the permeability coefficients of the three particle sizes. The recovery degree of permeability coefficient of $8-10 \mathrm{~mm}$ ceramsite is obviously higher than that of the other two particle sizes, which is about 1.2 times that of the other two. The permeability coefficient after recovery from 4$8 \mathrm{~mm}$ is only about $3 \%$ higher than that of $2-4 \mathrm{~mm}$. This may be because the proportion of $4 \mathrm{~mm}$ ceramsite in the 4$8 \mathrm{~mm}$ ceramsite used in the test is similar with that of 2$4 \mathrm{~mm}$ ceramsite. Therefore, it is very important to select the appropriate particle size and sieving the packing before filling.

The number of fluctuations required for the three fillers to restore the permeability coefficient to the maximum value when alleviating the blockage formed by different SS is shown in Table 5. This indicates that the use of the floating characteristics of the lightweight ceramsite itself to rearrange the gaps has a significant recovery effect on the wetland clogging formed by the three types of wastewater. However, considering that the protection height of wetland is generally $30 \mathrm{~cm}$, if you choose to increase the range of $30 \mathrm{~cm}$ and $40 \mathrm{~cm}$, you need to increase the construction height of the wetland wall, thereby increasing the construction cost. Therefore, if the subsurface wetland media bed is completely clogged, it can be floated 7-8 times within the wetland protection height range. In addition, it can also be used irregularly to adjust the height of the effluent water to float up and down the bed during daily operation, which can completely eliminate the clogging of the wetland substrate bed.

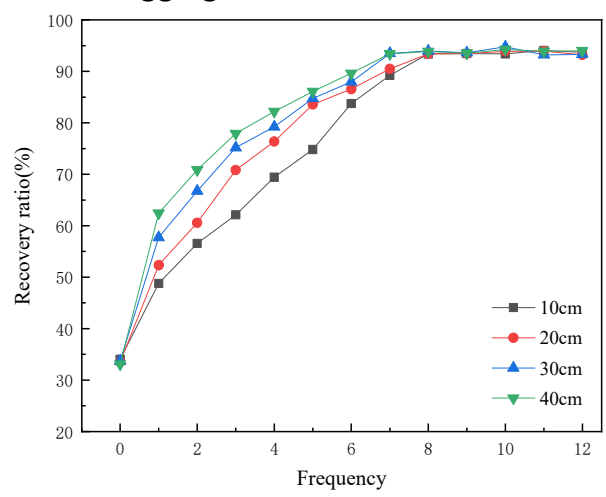

(a) $2-4 \mathrm{~mm}$ ceramsite

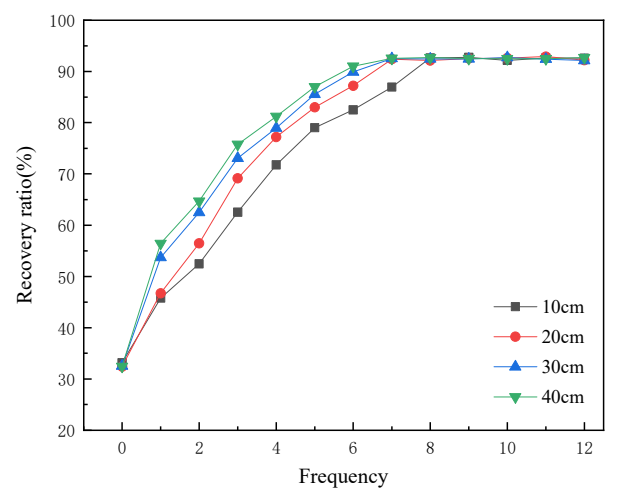

(b) $4-8 \mathrm{~mm}$ ceramsite 


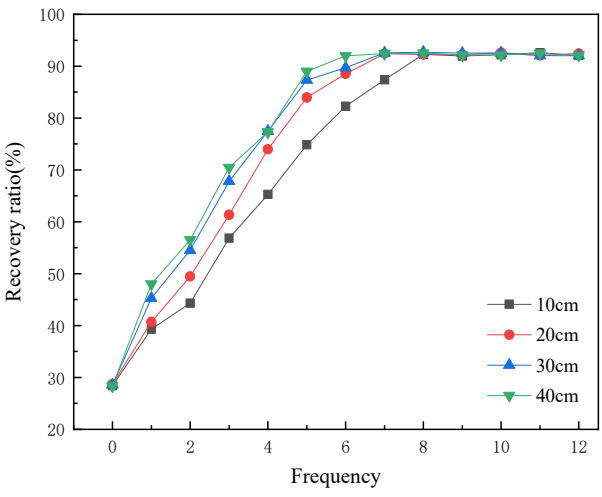

(c) $8-10 \mathrm{~mm}$ ceramsite

Fig. 4. Restitution degree of permeability coefficient of different fillers in zeolite powder wastewater

Table 4. Maximum flow recovery capacity (permeability coefficient) of packed beds with different particle sizes

\begin{tabular}{|c|c|c|c|}
\hline $\begin{array}{c}\text { Type of } \\
\text { SS }\end{array}$ & $\begin{array}{c}2-4 \mathrm{~mm} \\
\text { ceramsite }\end{array}$ & $\begin{array}{c}4-8 \mathrm{~mm} \\
\text { ceramsite }\end{array}$ & $\begin{array}{c}8-10 \mathrm{~mm} \\
\text { ceramsite }\end{array}$ \\
\hline Zeolite & $0.4152 \mathrm{~cm} / \mathrm{s}$ & $0.6111 \mathrm{~cm} / \mathrm{s}$ & $0.4553 \mathrm{~cm} / \mathrm{s}$ \\
\hline Bentonite & $0.4554 \mathrm{~cm} / \mathrm{s}$ & $0.6479 \mathrm{~cm} / \mathrm{s}$ & $0.4909 \mathrm{~cm} / \mathrm{s}$ \\
\hline Starch & $0.7090 \mathrm{~cm} / \mathrm{s}$ & $0.7573 \mathrm{~cm} / \mathrm{s}$ & $0.6835 \mathrm{~cm} / \mathrm{s}$ \\
\hline
\end{tabular}

Table 5. The frequency of fluctuations required for the packed bed with different particle sizes to recover to the maximum overflow capacity.

\begin{tabular}{|c|c|c|c|}
\hline $\begin{array}{c}\text { Fluctuation } \\
\text { amplitude }\end{array}$ & $\begin{array}{c}2-4 \mathrm{~mm} \\
\text { ceramsite }\end{array}$ & $\begin{array}{c}4-8 \mathrm{~mm} \\
\text { ceramsite }\end{array}$ & $\begin{array}{c}8-10 \mathrm{~mm} \\
\text { ceramsite }\end{array}$ \\
\hline $10 \mathrm{~cm}$ & 8 & 8 & 8 \\
\hline $20 \mathrm{~cm}$ & 8 & 7 & 7 \\
\hline $30 \mathrm{~cm}$ & 7 & 7 & 7 \\
\hline $40 \mathrm{~cm}$ & 7 & 7 & 6 \\
\hline
\end{tabular}

\section{Conclusion}

The four kinds of beds have a certain removal effect on the turbidity and SS in three kinds of wastewater. The four substrates have poor water purification capacity for bentonite wastewater, and have a better removal rate for zeolite powder and starch. This shows that the bed composed of $2-4 \mathrm{~mm}, 4-8 \mathrm{~mm}, 8-10 \mathrm{~mm}$ ceramsite and 5$10 \mathrm{~mm}$ gravel can effectively purify the water quality, and the wetland system it constitutes can also operate normally.

The four kinds of substrates are more likely to cause clogging of the wetland substrate bed when treating nondeformable inorganic particulate wastewater; in the absence of plants, compared to inorganic particulate clogging, the degree of clogging of the substrate is not obvious when treating wastewater containing organic suspended particulates.

After the wetland substrate floats up and down with the water level, the wetland clogging formed by the three types of suspended matter has been relieved to a certain extent, and the permeability coefficients all show an upward trend. This shows that the lightweight ceramsite can float up and down with the water flow relying only on a small change in the operating depth of the undercurrent wetland. The substrate can be re-arranged with the up and down of the water level, and the recombination of the substrate gaps can be rearranged, thereby effectively alleviating or even eliminating the clogging phenomenon of the undercurrent wetland. This operation mode does not require additional energy. It also avoids the regular replacement of substrate, greatly reduces the operation and maintenance costs of the wetland, and improves the stability of the wetland operation.

\section{References}

1. Li, Y.F., Tian, X.M., Liu, J. (2009) Application of constructed wetland to treatment of domestic sewage from residential area in northern region. J. China Water \& Wastewater, 12: 53-56.

2. García, J., Rousseau, D., Caselles-Osorio, A., et al. (2007) Impact of Prior Physico-Chemical Treatment on the Clogging Process of Subsurface Flow Constructed Wetlands: Model-Based Evaluation. J. Water, Air, and Soil Pollution, 185: 101-109.

3. Platzer, C., Mauch, K. (1997) Soil clogging in vertical flow reedbeds-mechanisms, parameters, consequences and ...Solutions?. J. Water Science and Technology, 35: 175-81.

4. Huang, F.Q., Chen, D.S., Wu, J.M., et al. (2017) Optimization of configuration and process for effectively mitigating substrate clogging in integrated vertical-flow constructed wetland. J. China Water \& Wastewater, 33: 31-36.

5. Tong, W., Zhu, W., Ruan, A.D. (2007) Primary study of clogging mechanisms of suhstrates in vertical flow constructed wetland. J. Hupo Kexue, 19: 25-31. 